\title{
Evaluating Students' Performance in a New Course Sequence with Economic and Design Principles in the Undergraduate Engineering Curriculum
}

\author{
W. R. Callen, S. M. Jeter, A. Koblasz, G. J. Thuesen/H. R. Parsaei, \\ H. R. Leep, T. A. Weigel/J. T. Luxhoj/C. S. Park/W. G. Sullivan \\ Georgia Institute of Technology/University of Louisville/Rutgers University/ \\ Auburn University/Virginia Polytechnic
}

\begin{abstract}
This paper presents some of the results obtained from a four-year project conducted at the Georgia Institute of Technology and Virginia Polytechnic Institute. For this project, four engineering science courses were modified to include economic and design principles. The primary objective of this experiment was to investigate on how the integration of economic principles with design can effectively be used to teach engineering science courses in the undergraduate engineering curriculum.
\end{abstract}

\section{Introduction}

In 1991. the National Science Foundation funded a multiyear project involving five universities. The project, entitled "The Integration of Economics with Design in the Engineering Science Component of the Undergraduate Curriculum" primarily focused on how the integration of economic principles with design can effectively be used to teach engineering science courses in the undergraduate engineering curriculum. The project also investigated how a stronger design orientation can improve understanding of the economic and technical tradeoffs required in developing processes to transform resources into products

Four courses were initially proposed and subsequently developed during the first two years of the project. These courses included Introduction to Engineering Mechanics, Elements of Thermal Energy Sciences \& Systems, Introduction to Electronics \& Electromechanical Systems, and Engineering Economy. These courses were primarily developed at the Georgia Institute of Technology and Virginia Polytechnic Institute and two of them were beta tested at the University of Louisville in the academic year of 1994-1995 [1-5].

\section{Review of results obtained from Georgia Institute of Technology's experiments}

A total of 274 students at the Georgia Institute of Technology took part in the experiment. Table 1 illustrates the distribution of the participating students. 
Table 1. Breakdown of participating students at Georgia Tech., Spring 1994

\begin{tabular}{llc}
\hline Course & & Number of Students \\
\hline ESM 2201 & Introduction to Engineering Mechanics & 60 \\
ESM 4805 & Introduction to Engineering Mechanics (Modified Course) & 27 \\
ME 3720 & Elements of Thermal Energy Sciences\& Systems (Traditional Course) & 75 \\
ME 4805 & Elements of Thermal Energy Sciences\& Systems (Modified Course) & 30 \\
EE 3710 & Introduction to Electronics\& Electromechanical Systems (Traditional Course) & 49 \\
EE 3825 & Introduction to Electronics \& E,lectromechanical Systems (Modified Course) & 33 \\
\hline
\end{tabular}

A pretest was designed and administered in the first week of the quarter. The objective of this pretest was to assess the students' preparation in the subject. Certain information was collected from all the students participating in this experiment. This information includes the following:

1. Gender

2. Major field of study

3. Class section

4. Level of study

5. Cumulative grade point average

6. Score on the SAT math examination

7. Score on the SAT verbal examination

8. Class percentile in high school

9. Score on the pretest

10 Score on the final examination

The data collected from courses listed in Table 1 were analyzed using the SAS software. In order to make this collected data more manageable, the gender, major, and level of study were classified into different groups.

1. Gender was divided into two classes (male and female).

2. Major was divided into classes (industrial engineering, other engineering, and nonengineering).

3. Level of study was divided into four classes (freshman, sophomore, junior, and senior).

The cumulative grade point average, SAT-math score, and SAT-verbal score were considered to be continuous independent variables.

Several procedures, including Correlation Analysis, General Linear Models, and Analysis of Covariance, were used to analyze the collected data. In the General Linear Model Procedure, the analysis was conducted using the final examination score as the dependent variable and the gender, class section, major, level of study, SAT-math score, SAT-verbal score, and grade point average as independent variables. All analyses were conducted at the 0.05 level of significance. The data from all six sections were pooled. It was found that the variable associated with class section was very dominant. The pooled data were then divided according to the three departments. Due to an insufficient amount of data, it was not possible to develop a statistically valid model for each department. It was further found that the design questions on the Electrical Engineering exams were far more challenging than the questions on the other exams. 
A model was "then generated for the courses in the other two departments (ESM and ME). The results indicated that the level of study, high school grade point average, college grade point average, and five first-order interactions (class section major, SAT-math class section, CLGPA major, HSGPA level, and HSGPA CLGPA) significantly affected the scores on the final exams. The statistical analysis also indicated that the students in the new courses performed as well as the students in the traditional courses.

\section{Review of results obtained from Virginia Polytechnic Institute's experiments}

Four sections of the engineering economy course were taught at Virginia Polytechnic Institute during the Fall Semester 1994. A total of 459 students participated in these sections. Table 2 displays the breakdown of the participants in this experiment.

\section{Table 2. Breakdown of participating students at Virginia Tech., Fall 1994}

\begin{tabular}{lc}
\hline Section & Number of Students \\
\hline ISE 2014-01 & 107 \\
ISE 2014-02 & 145 \\
ISE 2014-03 & 137 \\
ISE 2014-04 & 70 \\
\hline
\end{tabular}

The data collected from Virginia Polytechnic Institute was classified and analyzed using the same classification and statistical analysis techniques used for the Georgia Institute of Technology's experiments. The results indicated that at the 0.05 level of significance, the level, SAT-math score, and two interactions (level* major and level* CLGPA) significantly affected the scores on the final exams for all four sections. Analysis of the individual courses indicated the following:

1. There was a significant difference between the means of the two morning sections.

2. There was no significant difference between the means of the two afternoon sections.

The data from the morning sections and afternoon sections were pooled. The analyses were performed to compare the means of the final scores in the groups between the new and the old sections. The results indicated that there was no significant difference between the means of the morning and afternoon groups.

A comparison between the final scores of students who participated in the experiment in 1993 and 1994 was conducted. The results indicated that there was a significant difference between the means of the two mornings groups. A similar comparison was conducted between the afternoon sections 1993 and 1994. The results showed that there was a significant difference between the afternoon sections of these years. 


\section{Conclusions}

This article reported some of the results obtained from data collected from an integrated core of the engineering science courses developed and conducted at Georgia Institute of Technology and Virginia Polytechnic Institute. The primary objective of this research was to investigate how design activity, fully integrated with economic principles, can be effective y uti lized to teach the engineering science component of the undergraduate curriculum. Several statistical procedures were used to compare the results obtained from these experiments. All experiments were carried out at 0.05 confidence level. The results indicated that the students in the new courses performed as well as the students in the traditional courses.

\section{References}

1. G.J. Thuesen, W.G. Sullivan, W.R. Callen, S.M. Jeter, A. Koblasz, J.T. Luxhoj, C.S. Park, and H.R. Parsaei, "The Integration of Economic Principles with Design in the Undergraduate Curriculum," Proceedings of Frontier in Education, November 1992

2. G.J. Thuesen, S.M. Jeter, A. Koblasz, C.S. Park, H.R. Parsaei, W.G. Sullivan, and W.R. Callen, "Teaching Engineering Economics in the Context of Design," Proceedings of Frontier in Education, November 1994.

3. G.J. Thuesen, S.M. Jeter, A. Koblasz, W.R. Callen, H.R. Leep, H.R. Parsaei, T.A. Weigel, J.T. Luxhoj, C. S. Park, and W.G. Sullivan, "Evacuation of Teaching New Engineering Science Core Curriculum with Economic and Design Fundamentals," Proceedings of the Industrial Engineering Research Conference, May 1995.

4. G.J. Thuesen, S.M. Jeter, A. Koblasz, W.R. Callen, H.R. Leep, H.R. Parsaei, T.A. Weigel, C.S. Park, J.T. Luxhoj, and W.G. Sullivan, "Analysis of Results from Teaching Experimental Courses with Design and Economic Principles," Proceeding of the American Society of Engineering Education, June 1995.

5. G.J. Thuesen, "Design and Economics in Engineering Core Curriculum," The Engineering Economist, Vol. 40, No. 1, Fall 1994.

\section{Biographical Information}

WILLIAM R. CALLEN, JR. is an Associate Professor in the School of Electrical and Computer Engineering at the Georgia Institute of Technology. He received his B.S. (1968) in Physics from Princeton University, and his M. S. (1969) and Ph.D. (1971) in Applied Physics from Stanford University. He is a registered Professional Engineer and he received the Engineer of the Year Award in Education in 1989 for the Metro-Atlanta area. His Interests are in lasers and optics. 
Session $16 \hat{3} \hat{9}$

SHELDON M. JETER is an Associate Professor in the School of Mechanical Engineering at the Georgia institute of Technology. He received his Ph.D. in Mechanical Engineering from Georgia Institute of Technology in 1979. He is a registered Professional Engineer in Georgia. His interests are the design and simulation of energy systems and thermo systems analysis.

ARTHUR KOBLASZ is an Associate Professor in the School of Civil Engineering (Engineering Science and Mechanics Option) at the Georgia Institute of Technology. He received his Ph.D. in Engineering Science from the California Institute of Technology in 1976. He has interests in engineering mechanics and biomechanics with training in medicine. He also holds four patents.

HERMAN R. LEEP is an Associate Professor of industrial Engineering at the University of Louisville. Dr. Leep received his Ph.D. in industrial Engineering from Purdue University. Dr. Leep's teaching and research interests include engineering economy, advanced manufacturing systems, and manufacturing processes. He is a registered Professional Engineer and certified manufacturing Engineer.

JAMES T. LUXHOJ is an Associate Professor in the Department of Industrial Engineering at Rutgers University. He received his $\mathrm{Ph}$. D. In Industrial Engineering from Virginia Polytechnic Institute and State University. He is the Department Editor for Feature Applications and Technology Transfer for the IIE Transactions (IE Research).

CHAN S. PARK is a Professor in the Department of Industrial Engineering at Auburn University. He received his $\mathrm{Ph}$. D. in Industrial Engineering from Purdue University. He is a registered Professional Engineer. In 1990 and 1991, he was a winner of the Eugene L. Grant Award presented by the ASEE. He has served as a Manuscript Editor of The Engineering Economist since 1987.

HAMID R. PARSAEI is an Associate Professor in the Department of Industrial Engineering at the University of Louisville. He received his Ph.D. in Industrial Engineering from University of Texas at Arlington. He has served as an Area Editor for The Engineering Economist. In 1993, he was a winner of the Wellington Award from the Institute of industrial Engineers.

WLLLIAM G. SULLIVAN is a Professor in the Department of Industrial and Systems Engineering at Virginia Polytechnic Institute and State University. He received his Ph.D. from the Georgia Institute of Technology in Industrial Engineering. He is a registered Professional Engineer. In 1985 and 1992, he was a winner of the Eugene L. Grant Award from the A SEE. He is a Fellow in the Institute of Industrial Engineers and winner of the Alfred V. Bodine/SME Medallion from the Society of Manufacturing Engineers.

GERALD J. THUESEN is a Professor in the School of industrial and System Engineering at the Georgia institute of Technology. He received his Ph.D. in Industrial Engineering from Stanford University. In 1977 and 1989, he received the Eugene L. Grant Award from the ASEE and the 1989 Wellington Award from the Institute of Industrial Engineers. He served as an Editor of The Engineering Economist from 1981 through 1991. He is a fellow of the Institute of Industrial Engineers and a Fellow of the ASEE.

TERRENCE A. WEIGEL is an Associate Professor at the Department of Civil Engineering at the University of Louisville. He received his Ph.D. in Civil Engineering from University of Kentucky, Dr. Weigel also received an M.B.A degree from the University of Louisville. He is registered Professional Engineer in the state of Kentucky. His research and teaching interests include structures, strength of materials, and dynamics. 